Abstracta Iranica Iranica

Revue bibliographique pour le domaine irano-aryen

Volume 34-35-36 | 2017

Comptes rendus des publications de 2011-2013

\title{
Israel Finkelstein. Tell el-Ful Revisited: The Assyrian and Hellenistic Periods (with a New Identification)
}

\section{Astrid Nunn}

\section{(2) OpenEdition}

1 Journals

\section{Édition électronique}

URL : http://journals.openedition.org/abstractairanica/41556

DOI : 10.4000/abstractairanica.41556

ISSN : 1961-960X

Éditeur :

CNRS (UMR 7528 Mondes iraniens et indiens), Éditions de l'IFRI

\section{Référence électronique}

Astrid Nunn, «Israel Finkelstein. Tell el-Ful Revisited: The Assyrian and Hellenistic Periods (with a New Identification) ", Abstracta Iranica [En ligne], Volume 34-35-36 | 2017, document 28, mis en ligne le 15 juillet 2016, consulté le 30 septembre 2020. URL : http://journals.openedition.org/abstractairanica/ 41556 ; DOI : https://doi.org/10.4000/abstractairanica.41556

Ce document a été généré automatiquement le 30 septembre 2020.

Tous droits réservés 


\title{
Israel Finkelstein. Tell el-Ful Revisited: The Assyrian and Hellenistic Periods (with a New Identification)
}

\author{
Astrid Nunn
}

\section{RÉFÉRENCE}

Israel Finkelstein. « Tell el-Ful Revisited: The Assyrian and Hellenistic Periods (with a New Identification) ». PEQ, 143/2, 2011, p. 106-118.

L'A. traite de l'habitat sur le Tel el-Ful depuis l'âge du Fer à l'époque hellénistique. Finkelstein est connu pour ses idées décapantes. L'A. résume l'origine et le développement des théories sur ce site qui, selon lui sont le résultat d'une archéologie basée sur l'interprétation de la Bible et non sur celle du matériel archéologique. Ainsi refuse-t-il la théorie selon laquelle une grande forteresse fut construite au Fer I et qu'un mur de casemates protégeait ce site au Fer IIC. Il refuse également l'identification de Tel el-Ful avec la Gibeah biblique. La céramique indique la construction d'une tour néo-assyrienne de garde et son maintien dans un système défensif à l'époque hellénistique. En se basant sur ces nouvelles données l'A. propose Pirathon/Perath comme nom antique de Tel el-Ful. 


\section{AUTEURS}

\section{ASTRID NUNN}

Université de Munich 